\title{
História
}

\section{Entrevista com Maria Regina Maluf}

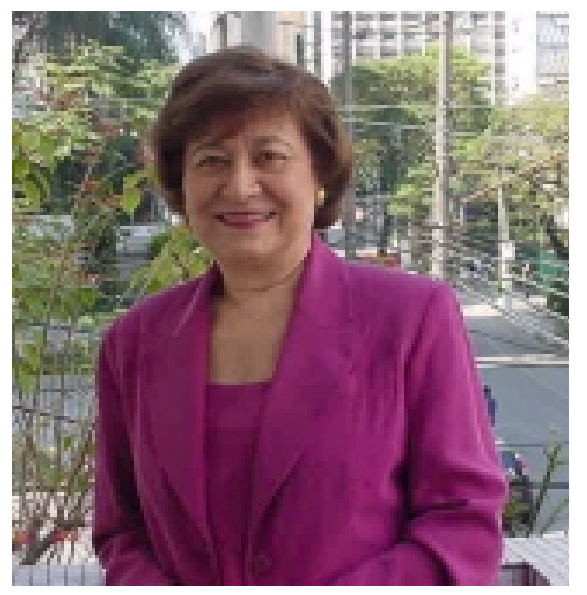

\section{Entrevistadora:Alacir Villa Valle Cruces}

MARIA REGINA MALUF é doutora em Psicologia pela Universidade de Louvain (Bélgica) e Livre Docente em Psicologia Escolar pela Universidade de São Paulo. Vem trabalhando ativamente na área da educação desde que voltou ao Brasil, após sua formação, seja como professora, seja como pesquisadora e orientadora em cursos de pós-graduação. Atualmente é professora de Psicologia do Desenvolvimento e da Educação do Programa de Pós-Graduação em Psicologia da Educação da Pontifícia Universidade Católica de São Paulo e de Psicologia do Desenvolvimento no Instituto de Psicologia da Universidade de São Paulo. Junto aos cursos de pós-graduação vem realizando pesquisas e orientando teses e dissertações em duas áreas principais: desenvolvimento infantil, com ênfase na aquisição inicial da escrita na pré-escola e ensino fundamental; formação do psicólogo, com ênfase no trabalho com educação. Seus orientandos, grupo no qual me incluo com enorme prazer, sabem de seu dinamismo, de sua solicitude, de sua grande experiência e dedicação que contagia a todos que estão a seu lado. Sempre envolvida em inúmeros projetos ela incentiva a participação e promove o desenvolvimento de seu grupo, com experiências sempre gratificantes em termos de aprendizagem e do crescimento que representam. Um exemplo deles, é o Grupo de Pesquisa "Escolarização Inicial e Desenvolvimento Psicológico" no qual diversos membros trabalham sob sua coordenação. Outro é a participação como membro da equipe constituída pela SIP desde 1997 para desenvolver estudos sobre Psicologia e Formação do Psicólogo nas Américas para o qual escreveu capítulos referentes ao Brasil nos livros já publicados: "Psicología en las Américas" e "Problemas Centrales para la Formación Académica y el Entrenamiento Profesional del Psicólogo en las Américas" dos quais eu tive a oportunidade de participar sob sua orientação e coordenação. Possui, além dessas, numerosas publicações em periódicos científicos e capítulos de livros, sobre temas de Psicologia da Educação e do Desenvolvimento e é membro de Sociedades Científicas Brasileiras e Internacionais nas quais tem prestado serviços de imensa relevância para o progresso da Psicologia como ciência e como profissão, sendo representante nacional em Sociedades Internacionais e Presidente da Comissão Organizadora do XXVI Congresso Interamericano de Psicologia que 
se realizou em São Paulo em 1997. Por tudo isso e pela grande contribuição que traz ao discutir conosco questões relativas ao preparo de profissionais para trabalharem na área da educação, às mudanças com as quais nos deparamos em nossa realidade e em nossa profissão que nos esclarecem e nos fazem refletir sobre nossas posições pessoais e profissionais, nosso reconhecimento.

Cruces: Você poderia se apresentar para nós e falar um pouco sobre sua formação e sua trajetória profissional? Sei que você tem uma formação diferente da nossa por ter sido feita em Louvain, na Bélgica, e acredito que ela caracteriza muito de suas concepções, de sua maneira de atuar e de fazer Psicologia, não é?

Maluf: O meu interesse pela educação é "quase genético", nascido do cotidiano com uma mãe apaixonada pelo ensino de crianças, nos anos longínquos em que ser professora era não só uma missão de vida e cidadania como também um reconhecimento de mérito pela sociedade e pelos órgãos públicos responsáveis pela educação nacional. As circunstâncias e um certo nível de escolha pessoal levaram-me ao curso de Psicologia depois de cursar Pedagogia.

Minha formação em psicologia, que se estendeu até o doutorado, numa universidade estrangeira, de "primeiro mundo", a Universidade Católica de Louvain, na Bélgica, proporcionou-me um modo de entender a ciência psicológica que em alguns aspectos diferenciou-se do que mais tarde verifiquei que era mais comum no Brasil, nos cursos de psicologia nascentes: estamos no final dos anos 60. É verdade que, de volta ao meu país, que se debatia aprisionado por um governo de exceção, foi necessário um período de re-adaptação para dar-me conta das peculiaridades de se fazer psicologia da educação nas contingências políticas, socioculturais e econômicas vigentes em um país integrante da América Latina conturbada daqueles anos difíceis, chamados no Brasil de anos de chumbo.

Penso que recebi uma formação que me permitiu uma preocupação constante com a demarcação do conhecimento científico, com a ética e com as necessidades concretas da sociedade brasileira, na complexidade das interações que nos colocam problemas e contradições nunca completamente resolvidas. Por outro lado, minha convivência, às vezes muito intensa, com outras culturas - quero dizer, em diferentes países e continentes, com pessoas diversas quanto à etnia, religião, visão de mundo, escolarização- bem como as numerosas oportunidades de intercâmbio com pesquisadores psicólogos através de reuniões científicas, congressos, sociedades científicas internacionais, fizeram com que se consolidasse em mim uma visão de ciência muito processual, em construção, distante de toda e qualquer perspectiva dogmática e cristalizada. Não me refiro à adoção de uma epistemologia relativista e tampouco ao ecletismo. Refiro-me ao reconhecimento efetivo e ao respeito pelas diferenças, ao reconhecimento da dignidade inerente do outro, à provisoriedade de muitas de nossas convicções. Por muito convictos que estejamos de nossas certezas, tudo pode mudar. Sem levar ao pé da letra, esta postura tem a ver com a tese de Heráclito para quem a água do rio nunca é a mesma. Resta responder: e o rio é o mesmo? Caberá a cada um decidir, segundo o seu conceito de rio. E haveremos de convir que diferentes respostas poderão ser igualmente verdadeiras!

Para nosso pensamento ocidental analítico e linear, é as vezes muito difícil entender que para uma mesma questão possa existir mais de uma resposta verdadeira. Mas pode! Se as potencialidades humanas são universais, como admito, é porém a cultura que decide quais delas se expressam e a forma de que se revestem. Somos semelhantes a todos os indivíduos humanos em alguns aspectos, semelhantes a alguns em outros aspectos e em alguns aspectos somos únicos. A formação que recebi, os intercâmbios nacionais e internacionais que experienciei, as reflexões sobre anos de prática docente deram-me uma mente muito aberta e me ensinaram a conviver com a dúvida sem me sentir desconfortável.

Tive uma formação muito generalista. E isto foi bom porque tive também muitas oportunidades de especialização. Mas, a formação generalista, segundo observo, pode ser danosa se não for seguida por alguma forma de especialização. As vias que percorri me ensinaram a conviver bem com a dúvida científica, isto é, admito que a ciência psicológica me ensina muitas coisas mas a experiência pessoal também ensina e a assimetria entre essas duas fontes de conhecimento não é constante. Aprendi a fazer escolhas provisórias. Por isso não sou eclética, no sentido de não comprometerse com coisa alguma, no sentido do vale tudo. Mas tomo decisões diversas em circunstâncias diversas. Não adoto princípios universais fora do tempo e do espaço. A história dos grandes sofrimentos da humanidade nos ensina muita coisa. As duas grandes guerras do início 
do século 20 fizeram ruir grandes esperanças e confianças apressadas no poder humanizador do progresso das ciências. Ciência e técnica produziram terríveis armamentos e procedimentos que transformaram sonhos em pesadelos. Conseqüentemente, convivo bem com a psicologia científica atual na qual coexistem paradigmas diversos. Nenhum deles me fornece todas as respostas de que preciso para explicar a complexidade do comportamento humano. Particularmente quando se trata de Psicologia e Educação: em circunstâncias diferentes precisamos de respostas diferentes, embora as coordenadas sejam aparentemente as mesmas. Estas respostas podem vir da psicanálise, do comportamentismo, das neurociências do comportamento, da fenomenologia, do cognitivismo, do culturalismo... Meu ponto de partida é o problema, ou seja, a questão concreta para a qual estou procurando uma explicação. Costumo alertar meus estudantes para a necessidade de se fazer escolhas, mesmo que sejam escolhas muito provisórias, para que se possa conduzir pesquisas dentro dos paradigmas aceitos na atual sociedade do conhecimento em que estamos inseridos. Na contemporaneidade o saber epistemológico é um convite à reflexão constante, não no abstrato que gera falsa erudição, mas sim na exposição ao real com o qual nos deparamos e que deve conduzir-nos ao movimento constante prática-teoria-prática. É deste movimento que, segundo acredito, nasce o conhecimento útil com potencial transformador dos indivíduos e sociedades, cujo bem-estar deve ser objetivo do pesquisador e do profissional da Psicologia e da Educação.

Cruces: Em que medida você considera que seja importante o treino em pesquisa na formação do psicólogo e em especial para preparar o psicólogo para trabalhar na área da educação? Como conciliar essa necessidade com as demais da formação em um curso noturno, por exemplo?

Maluf: Pesquisar é produzir conhecimento: conhecimento útil. A utilidade do conhecimento não é sempre evidente, mas assumo que ele sempre serve a interesses. É portanto indispensável ao pesquisador buscar entender na medida de suas possibilidades a que interesses ele serve quando produz conhecimento.

Afirmamos com facilidade que a formação do psicólogo precisa incorporar a pesquisa. Penso que ninguém atualmente afirmaria o contrário. Mas, formar para a pesquisa parece estar tomando a forma de um fetiche. Há que responder: o que significa, no concreto, formar para a pesquisa? Diferentes significações são facilmente atribuíveis a um mesmo enunciado. Os teóricos da representação social provavelmente concordariam comigo e verificariam essa hipótese através de pesquisa sistemática. Para mim, formar-se em pesquisa significa aprender a não se contentar com respostas prontas, sobretudo com aquelas envoltas em falsas erudições e em certezas apoiadas em pressupostos distantes da verificação e da controvérsia. A pesquisa é uma especialidade. É falso afirmar, por exemplo, que todo educador, ou professor, é ou tem que ser pesquisador! É possível ser um excelente educador ou professor sem ser pesquisador! Assim como um excelente pesquisador pode ser um péssimo professor! Pesquisar exige um saber específico, que envolve várias habilidades a serem sistematicamente aprendidas. Formar-se em pesquisa significa também aprender a fazer perguntas para o real e distinguir entre aquelas perguntas que podem ser respondidas através de procedimentos metodológicos apropriados e aquelas que não são respondíveis no contexto da ciência psicológica atual.

A certeza é inimiga da ciência. Também o é o ceticismo. Os paradigmas da pós-modernidade nos convidam a refletir sobre a complexidade, sobre a organização do caos, sobre a diversidade e colocam no centro das preocupações o papel da cultura na constituição de nossas funções psicológicas superiores, no sentido em que Vygotski as entendeu. Alguns psicólogos contemporâneos enxergam a psicologia como psicologia cultural. Não penso que esse deva ser o ponto de partida para a formação na pesquisa, mas é um horizonte a ser apontado para os jovens pesquisadores. É preciso que eles o tenham como horizonte mas dêem pequenos passos. Dar pequenos passos significa estudar métodos, aprender diferentes delineamentos lógicos, refletir e experimentar formas possíveis de coletar dados, capacitar-se para entender o valor e os limites dos diferentes tipos de análise, confrontar o real com os conceitos verbais utilizados para expressá-lo.

Preparar o psicólogo para trabalhar na área da educação significa introduzi-lo no conhecimento do fenômeno educação e instrumentalizá-lo para trabalhar em instituições, particularmente na escola, instrumentaliza-lo para entender o papel determinante das interações: adulto-criança, criança-criança, adulto-adulto, pais, funcionários, professores. Para trabalhar bem na área da educação o psicólogo deve ter adquirido 
competências e habilidades para compreender e agir sobre as condições em que os comportamentos se constituem e se modificam. Assim será capaz de promover o desenvolvimento e a aprendizagem. Essa é uma postura diametralmente oposta à produção de diagnósticos que cristalizam e estigmatizam os indivíduos e acabam por dificultar senão mesmo impedir sua evolução e crescimento psicológico. O psicólogo educacional, ou escolar, ao qual nos referimos, toma como ponto de partida o reconhecimento das capacidades dos educandos: o que eles já são, já sabem ou já podem fazer e ajuda-os a ir além. Jamais se apóia no que o educando ainda não sabe ou ainda não é.

Você mencionou cursos noturnos. Penso que eles ainda são o patinho feio de nosso sistema educacional. A demanda reprimida de jovens brasileiros que querem aceder ao ensino superior é enorme e crescente. Fazer um curso superior ainda é imenso privilégio. Um grande numero de jovens de comunidades pobres que trabalham para sustentar-se, quando acedem às instituições de ensino superior só têm como opção dirigir-se a cursos noturnos. Em muitos desses cursos também se formam psicólogos para o trabalho em educação. Ali se encontram jovens com grandes potencialidades, precocemente amadurecidos para a vida adulta, com ricas experiências de vida. Não podemos simplesmente transpor para eles um conjunto de práticas pensadas para outra realidade. Conhecemos mal essa categoria de estudantes. Temos que exercitar nessa realidade o que sabemos sobre produzir conhecimento para poder agir melhor, descrever e explorar o real, o que significa sobretudo ouvir os atores desta cena. Temos que desenvolver formas de ensino adequadas a essa realidade, explorar as possibilidades e contornar os limites: horas de estudo, bibliotecas, aquisição de livros, condições de estágio.

\section{Cruces: Que mudanças significativas você vê na atuação dos psicólogos que trabalham com educação desde a sua volta para o Brasil até os dias de hoje?}

Maluf: A atuação de psicólogos na educação sofre de vícios já abundantemente explorados na literatura crítica da área: atuam como técnicos sem conhecimento teórico; abusam da psicometria que conhecem mal; patologizam dificuldades dos escolares; psicologizam questões que são de caráter social, econômico ou cultural; não lidam adequadamente com o contexto escolar ou familiar, etc.
É essa uma visão crítica, consolidada nos anos 80, que desempenhou importante papel histórico, mas que hoje só reflete parcialmente a realidade. Falta-lhe dinamismo transformador na medida em que é externa e conduz à culpabilização das vítimas. Sim, porque muitos dos teóricos-críticos que integram a categoria dos formadores de psicólogos contentam-se com análises externas e cristalizam o problema eximindo-se de estudar soluções.

A atuação que está sendo, com razão, criticada, nasceu dos cursos de formação, foi ensinada e foi aprendida. Não penso que o problema esteja na Psicologia como ciência, à qual alguns atribuem caráter ideológico de natureza simplista e reducionista. Já concordei, no passado, com esta análise, porém hoje a considero equivocada. Ela transfere nossa responsabilidade para uma espécie de forças ocultas que atuariam mais além de nós mesmos, como se fôssemos joguetes de forças sociais, sem nenhuma possibilidade de escolha, de decisão e consequientemente despidos de responsabilidade.

Considero esta postura como gravemente equivocada, sobretudo na contemporaneidade em que a preocupação com a ética renasce face à necessidade de se resgatar a construção de um mundo mais humano. Se, como reconhecemos, profissionais de psicologia aprenderam e utilizaram o aprendido para reforçar privilégios e manter desigualdades numa sociedade enormemente desigual, é tempo de resgatar nossos erros e produzir mudanças na formação. Antes de ser esse um problema científico é um problema de formação de consciência social, de opção por valores humanizadores.

Há que se distinguir o conhecimento em si e o uso do conhecimento. O conhecimento em si supõe, na Psicologia e na Psicologia Educacional, a exigência de atualizar-se no saber científico, basicamente em suas duas grandes vertentes: por um lado os processos básicos e sua influência no comportamento e por outro a influência da cultura, ou seja, os determinantes socioculturais do comportamento. Entendo que o uso do conhecimento deve supor a ética e defendo uma visão de mundo humanizadora, o reconhecimento da diversidade, a luta contra as diferentes formas de discriminação social e de exclusão. Nas escolas isto deve significa que o conhecimento psicológico pode ajudar os professores a enfrentar, no micro e face ao macro, o cotidiano da produção de sentido de sua ação.

Para alguns, cabe ao psicólogo escolar atuar também no âmbito do sociólogo, do economista, do político, do antropólogo, do filósofo. Meu ponto de vista é mais 
modesto. Penso que o psicólogo escolar pode ajudar o professor a lidar de modo mais eficaz com os processos de aprendizagem e de desenvolvimento, levando seus alunos a aprender mais e melhor; pode conduzir o corpo escolar a conquistar para si uma vida mental mais saudável; pode agir para abrir eficazmente as portas da escola para as famílias e até mesmo para a comunidade local de modo que sejam desenvolvidas ações conjuntas em benefício de todos; pode usar seu conhecimento para levar os alunos a aprender melhor, mais além do individualismo, usando técnicas de desenvolvimento grupal; pode identificar problemas e fazer os encaminhamentos necessários para que a atuação de outros profissionais possa completar a sua; pode trabalhar com a comunidade escolar técnicas apropriadas para prevenir ou enfrentar mazelas contemporâneas como são as diversas formas de violência que atingem a escola, hábitos em consolidação de porte de armas, comércio e consumo de drogas. Cabe ao psicólogo sobretudo explicitar comportamentos pro-sociais como a solidariedade, a cordialidade, a proteção ambiental, o respeito pela coisa pública. Quem melhor do que o psicólogo, particularmente o psicólogo na escola, para ensinar as pessoas a lidar melhor com o comportamento próprio e alheio para viver melhor?

Acredito que esse psicólogo já existe e atua em vários lugares em nosso pais. É hora de torna-lo mais visível e de apostar na formação desse novo psicólogo escolar.

Cruces: E, pensando em mudanças, como você analisa esse movimento de discussão e preparo de novas diretrizes curriculares em Psicologia? O que você poderia nos dizer sobre as diretrizes que estão sendo analisadas para serem votadas pelo MEC? Que implicações você acredita que possam ter sobre a formação e a atuação dos futuros profissionais?

Maluf: De fato, como todos sabemos, os Cursos de Graduação em Psicologia ainda não conseguiram ter aprovadas e homologadas suas diretrizes curriculares. Diferentemente de outras áreas do conhecimento, que atendendo à nova LDB já alcançaram o consenso que lhes permitiu delinear o perfil de profissional que querem formar em seus cursos de graduação e as bases para formá-lo através de diretrizes, a Psicologia, decorridos 8 anos, ainda sustenta acalorados debates em torno da questão. Seguindo os mesmos procedimentos utilizados com outras áreas do conhecimento, o MEC atribuiu a uma comissão de especialistas em psicologia a tarefa de elaborar as diretrizes curriculares que, seguindo a nova legislação, deverão substituir as exigências do antigo currículo mínimo, já ultrapassado face às características dos tempos atuais. Apesar das muitas consultas e debates já realizados, não se chegou ainda a um consenso razoável expresso pelas associações e sociedades que reúnem os psicólogos brasileiros, que têm se manifestado junto ao CNE e junto ao MEC. Conseqüentemente, estamos ainda em compasso de espera ou em fase de debates, conforme se prefira entender o momento atual.

De meu ponto de vista considero que é tempo de que a área se organize e se consolide em torno das posições que se revelarem mais representativas da maioria. Não se deve esperar um consenso total quando se adota procedimentos democráticos. Espera-se isto sim a manifestação das várias posições e uma tomada de decisão que seja representativa da área.

Trata-se de formar o profissional no nível da graduação e por essa razão considero fundamental a manifestação dos cursos de psicologia existentes. De meu ponto de vista, a proposta apresentada ao CNE pela comissão de especialistas e revisada em alguns pontos polêmicos após parecer da relatora, preenche satisfatoriamente os requisitos que se espera de diretrizes curriculares. A proposta em meu entender é flexível, é atual, adere ao princípio de uma formação generalista na graduação em psicologia, questão essa já exaustivamente discutida e sobre a qual existe enorme consenso na área. Ao recomendar que os cursos ofereçam aprofundamento em algum domínio do conhecimento e da atuação profissional, a proposta visa criar condições para que o aluno saia da graduação melhor preparado para atuar em algum domínio dentre os muitos que a psicologia possui. Penso que isto é importante e desejável, uma vez que os estudantes enfrentam um período longo de formação -cerca de 5 anos- , com custos altos e diretos para eles mesmos na maioria dos casos, posto que freqüentam instituições privadas. É de se esperar que em muitos casos e possivelmente na maioria deles, a formação especializada só ocorra muito mais tarde, ou mesmo não ocorra. Assim, ao salvaguardar a formação generalista mas garantir ao mesmo tempo algum aprofundamento em campo de conhecimento e atuação a ser definido pelo próprio curso segundo suas possibilidades, estaremos mais próximos de garantir que o egresso possua competência e habilidade para atuar imediatamente após um curso de formação que já se estendeu por 5 anos. 
Eu gostaria de acrescentar que a formação para atuar na área clínica merece considerações aparte, pela complexidade dos riscos que comporta e levando em consideração que os procedimentos atualmente em vigor em nosso país permitem que um jovem recémformado num curso generalista obtenha licença imediata junto aos Conselhos profissionais e atue por si só em um consultório particular. Esta me parece ser uma questão grave que ainda não foi objeto de análises condizentes com sua importância e consequiências que implica. Porém prefiro não discuti-la no âmbito desta conversa, pois creio que me alongaria mais do que o previsto nesta entrevista. Limito-me então a agradecer pelo convite e oportunidade preciosa de me comunicar com colegas e estudantes de psicologia através da Revista. Muito obrigada. 